\title{
From Discovery to Invention
}

Sociological study of academic correspondence

\section{Michel Dubois}

\section{OpenEdition}

\section{Journals}

Electronic version

URL: http://journals.openedition.org/ress/2772

DOI: $10.4000 /$ ress. 2772

ISSN: 1663-4446

\section{Publisher}

Librairie Droz

\section{Printed version}

Date of publication: 27 November 2014

Number of pages: 7-42

ISBN: 978-2-600-01866-1

ISSN: 0048-8046

\section{Electronic reference}

Michel Dubois, « From Discovery to Invention », Revue européenne des sciences sociales [Online],

52-2 | 2014, Online since 01 January 2018, connection on 01 May 2019. URL : http://

journals.openedition.org/ress/2772 ; DOI : 10.4000/ress.2772 


\title{
FROM DISCOVERY TO INVENTION \\ SOCIOLOGICAL STUDY OF ACADEMIC CORRESPONDENCE
}

MICHEL DUBOIS

Paris Sorbonne University/GEMASS-CNRS

michel.dubois@cnrs.fr

\begin{abstract}
The article proposes a sociological analysis of the epistolary relationship between two forerunners of the social study of science and technology: Robert K. Merton and Seabury C. Gilfillan. Based on primary source archived at Columbia University — a set of letters exchanged between 1932 and 1976 - it develops a relational approach of epistolary communication that aims to reassess the traditional (and mostly economic) genealogy of innovation studies. The study of the invisible college of invention through the private and informal interactions allows us to specify the cognitive, normative and strategic components of academic correspondance but also to explain the durable separation of the sociological study of science (discovery) and technology (invention) observed until the end of the 1970s, before the emergence of the Science, Technology and Society (STS) field.
\end{abstract}

Keywords: epistolary relationship, innovation, invention, invisible college, Robert K. Merton, scientific communication, Seabury C. Gilfillan.

Résumé. L'article propose une analyse sociologique de la correspondance entre deux pionniers de l'étude des sciences et des techniques: Robert K. Merton et Seabury C. Gilfillan. À partir d'un matériau original archivé à l'Université Columbia - un ensemble de lettres échangées entre 1932 et 1976 - nous développons une approche relationnelle de la communication épistolaire qui permet de réévaluer la généalogie traditionnelle (le plus souvent économique) des études sur l'innovation. L'étude du collège invisible de l'invention à partir d'interactions privées et informelles est l'occasion de préciser les composantes cognitive, normative et stratégique de toute correspondance académique mais également d'expliquer la séparation durable de l'étude des sciences (découverte) et des techniques (invention) observée jusqu'à la fin des années 1970, avant l'émergence du domaine Science, Technologie et Société (STS).

Mots-clés: collège invisible, communication scientifique, innovation, invention, relation épistolaire, Robert K. Merton, Seabury C. Gilfillan. 
Science and technology are often described as two areas of sociological study that converged only recently at the end of the $20^{\text {th }}$ century, with the emergence of the field now known as Science, Technology and Society (STS) ${ }^{1}$ (MacKenzie and Wajcman, 1985; Bijker, Hughes and Pinch, 1987). This article focuses on an early missed encounter between the sociological studies of science and technology. A largely forgotten episode set at a time when contemporary mapping of objects, research programs and their respective boundaries, were still to be invented. It relies mainly on an original material: the correspondence of Robert K. Merton deposited in the Rare Book and Manuscript Library (RBML) of Columbia University.

A recent study has characterised the nature and the extension of the Mertonian epistolary network: nearly 650 scholars from all over the world and whose letters cover the period from 1930 to 2003 (Dubois, 20I4). This informal material offers new insights on various relational components of academic life mostly unreachable through other sources, such as public reports or publications. My aim here is to give a detailed account of one unit of this global communication network: the correspondence between Merton and Seabury Colum Gilfillan. If the catalog of Merton's correspondence is so rich, including letters from most of the prestigious names in the $20^{\text {th }}$ century sociology, why then am I focusing on this specific relationship between Merton and Gilfillan?

A first set of reasons stems from their common features. The lives of the two sociologists span most of the $20^{\text {th }}$ century: Gilfillan was born in 1889 and died at the age of 97, Merton was born in 19ro and died at the age of 92. Both were pioneers in science and technology studies who chose to make sustained contributions to this research area during the same period. Both finally were aware that they belonged to a scientific area whose lasting institutionalisation required the development and control of specific organisational "instruments”. In his Episodic Memoir, Merton (1977) carefuly described his organisational involvement in various learned societies in the social sciences. In the immediate postwar period, Gilfillan was the instigator of an autonomous organisation- the Society for the Social Study of Invention (S.S.S.I.)—officially created in 1947. 
The second set of reasons that justifies interest in the epistolary relationship between Merton and Gilfillan stems from their strong dissimilarities. Although Merton and Gilfillan belong to the same "invisible college", their academic status differed significantly: whilst the former was to quickly become a tenured professor at Columbia University, the latter would remain a research associate at the University of Chicago. The institutional background of this relationship was against that of two departments of sociology — Columbia and Chicago-having distinct approaches to the scientific nature of their discipline (Abbott, 1999). But the most salient difference between the two lies undeniably in their respective positions in the collective memory of the discipline. While Merton is generally seen as the main founder of the sociology of science, who now remembers Gilfillan and his sociology of invention? More widely, who can now recall

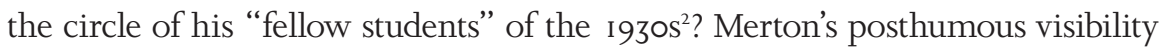
seems inversely proportional to Gilfillan's posthumous obliteration.

This paper proposes a sociological approach to the epistolary relationship between Merton and Gilfillan designed not only to describe the asymmetrical nature of their academic relation but more broadly to account for the rise and disappearance of an ephemeral research collective in the early field of social studies of science and technology. It is therefore my aim to contribute to a long-standing research tradition on the formation of obliteration, failure or ignorance in social sciences (Dubois, 1994). This is a complementary approach to the one centred on disciplinary entrepreneurship strategies (Karady, 1979) or "iconicisation" of great contributors to social theory (Bartmansky, 2012). 


\section{ACADEMIC CORRESPONDENCE AS A SOCIOLOGICAL PHENOMENON}

Correspondence is a well-established form of scientific communication. In his early writings, Merton emphasises the social consequences of the improvements of the postal service. Without replacing the traditional practice of "scientific journeys", the postal service significantly accelerated the circulation of information among scientists all over Europe:

Correspondence between scientists, which constituted the only means of scientific communication in the early seventeenth century, was facilitated by improvements in postal service. The voluminous correspondence of such "professional intelligencers" and scientists as Mersenne, Peiresc, Collins, Wallis, Boyle, Huyghens, and Oldenburg testifies to the felt need for interaction between the various investigators. Spatial separation between scientists is not of great moment if there are ready means of communication (Merton, 1938, p.582-583).

Merton also highlights a well-documented feature of most communication networks: the unequal centrality of social actors. The epistolary exchanges that he studied were often based around a few major individuals described as "catalysts". Marin Mersenne is from this point of view an archetypal figure by his centrality — a betweenness centrality in the language of network analysis — and his ability to stimulate the talent of his correspondents: "Father Mersenne must be considered the very archetype of the catalyst. He recognised the merit of Campanella, Bacon, Galileo, Herbert of Cherbury and sought fitting recognition of them. He was the friend of great men who were at odds with one another and communicated only through him" (Merton, 1960, p.43I). The study of scientific correspondence is useful not only to reconstruct the relational structure which influences the dissemination of knowledge, but also to capture the nature of scientific discussion and the orientation of the collective attention toward specific areas, thematics or subjects. However one should be aware of the special status of this material. Indeed the content of a letter is rarely the simple prefiguration or early manifestation of what will be later publicly communicated through other means. The private and fugitive dimensions of correspondence are contrasting with the well-documented validational and archival functions 
of publication. Furthermore, epistolary exchanges are characterised most of the time by their informal nature. Like any other informal communication mode, they enable the circulation of information that is sometimes difficult or simply impossible to include in publications or public reports: advices, speculative interpretations, vague opinions, etc. Correspondence has also a high degree of permissiveness. Freed from the constraints associated with publicisation, scientists have access to a wide range of expression in the exchange of suggestions and criticism, and no public engagement of their individual responsibility.

Merton sometimes gives the impression of ignoring this difference in nature between formal (publication) and informal communication (private correspondence). He frequently uses in his own publications extracts from correspondence as empirical data to support his sociohistorical analyses. Writing about the first steps of George Sarton in the US academic world, he quotes extensively from correspondence between Sarton and Robert S. Woodward, the second president and successful organiser of the Carnegie Institution of Washington (Merton, Thacray, 1972). Reconstructing the origins of the prosopographical method, Merton quotes the correspondence between Francis Galton and Alphonse de Candolle. What emerged from this correspondence, writes Merton, "was the strong and shared sense that it was important to have what would eventually be described as 'indicators' of scientific eminence" (Merton, 1977, p.30). A final example, is that when he was recalling the direct and indirect influence of Paul Lazarsfeld on his academic life, Merton quoted from a letter sent by Karl Popper to Michael Cavanaugh that explains partly the absence of a direct tie between Popper and Merton:

I am sorry that I have obviously been unjust and unfair to Merton by not studying him sufficiently. [...] I had been told (not only by Paul Lazarsfeld himself but also by other people) that Merton was a friend and kind of pupil of Lazarsfeld. And Lazarsfeld, whenever he spoke about scientific methodology only said nasty things about me. So I had very little inducement to look more deeply into Merton's work which I deeply regret (Letter from Popper, cited by Merton, 1998, p.I8I). 
Merton also does not hesitate to quote from his own correspondence. Some of his private exchanges with Thomas Kuhn are reproduced in his analysis of the emergence of the sociology of science (Merton, 1977). These quotations were at that time most useful to show the complementary nature of the Kuhnian and Mertonian approaches to science-at least in the mind of their founders. Finally, beyond the occasional uses of letters as "raw data" in support of a sociological demonstration, it is worth remembering Merton's personal preference for his book On the Shoulders of Giants (1985) which is constructed as an epistolary book. Built on the literary model of Tristram Shandy by Laurence Sterne, this book is a long response to a letter from a Harvard colleague - the historian Bernard Baylin. It also provided Merton with the opportunity to reconstruct the socio-historical genealogy of a famous phrase generally attributed to Isaac Newton and used by scientists to define, in a cumulative manner, their relationship with their most illustrious predecessors: "If I have seen farther, it is by standing on the shoulders of giants". The original tone of this book - which displays a freedom and an irony not found in any of Merton's works-shows, however, that the author was well aware of his unusual stylistic device. He knew that by methodically following the essence of the Shandean method he potentially laid himself open to the charge of "unscholarly conduct".

\section{CORPUS AND METHODOLOGY}

The RBML provides access to several series of documents covering different periods ${ }^{3}$. Series II contains letters written by Merton (original or duplicate according to the available state of technology), requests and/or responses (original or duplicate) sent by correspondents, and sometimes letters not initially intended for Merton but whose authors had chosen to send him a copy for various reasons. These letters are mostly typed. Merton used different models of typewriters (a varityper, an IBM Selectric II in particular) and various techniques of duplication (carbon copy, xerography, etc.). Handwriting was strictly reserved for dedication or annotations, sometimes extensive and detailed (with various ink colours), on the margins of the letters both received and sent. Whereas my general approach 
to Merton's correspondence was based on the analysis of approximately 450 letters exchanged with more than a hundred contacts (Dubois, 2014), I choose here to restrict myself to a smaller set: 29 letters kept by Merton and exchanged between him and Gilfillan over the period I932-1976.

\section{I. RELATIONAL APPROACH TO CORRESPONDENCE}

The corpus is distributed over the period 1932-1976 in the following manner: 1932 (6 letters), I933 (I), I934 (I), I935 (3), I936 (I), I947 (5), I 948 (2), I949 (3), I968 (I), I97 I (2), I973 (I), I 975 (2), I 976 (I). Three major periods can be distinguished. In the first period (1932-1936), letters mostly concern the formation of the field of science and technology studies. The second period, just after World War II (1947-1949), is mainly concerned with the creation of an organisational structure: the Society for Social Studies of Invention. The third period (1968-1976) strongly focuses on sociohistorical studies conducted by Gilfillan on the social consequences of technical inventions-particularly those associated with lead (Gilfillan, 1965).

Table I below shows the thirty authors, themes or objects with the highest citational frequency for the entire corpus (the names of Merton and Gilfillan have not been cited here for obious reasons).

Table I. Names and terms most frequently cited (by decreasing order of frequency)

\begin{tabular}{|c|c|c|c|}
\hline \multicolumn{2}{|c|}{ INDIVIDUALS } & OTHERS TERMS: CATEGORIES, ORGANISATIONS, ETC. \\
\hline Ogburn & Lienau & invention & publish \\
Kaempffert & Hamilton & social & progress \\
Carr & Graham & society & idea \\
Rossman & Schumpeter & patent & copy \\
Gittler & Patterson & interest & committee \\
Oliver & Parsons & field & organization \\
Douglas & Lowell & book & aaas \\
Sanders & Jaffe & inventor & race \\
Hamor & Cochran & sociology & labor \\
Payne & Zuckerman & article & Chicago U. \\
Dyke & Wilson & class & publication \\
Usher & Weinland & economic & PhD \\
Sorokin & Veblen & capital & membership \\
Dewhurst & Taylor & journal & director \\
Stern & Stouffer & secretary & chairman \\
\hline
\end{tabular}


Unsurprisingly, the thematic column highlights the notions of invention (235 references), social (79) or society (74) and patent (68), far ahead of the others. It is worth noting that the notion of "innovation" is not used at all in the corpus. The categories of invention and patent are in fact central for the whole corpus and generally thought of as constituting an emerging field of research in sociology. Correspondence is frequently used to discuss the content of articles, chapters, books and copies of articles and letters. It also has a strong organisational dimension ("secretary”, “committee”, “chairman”, A.A.A.S., etc.) related to the Gilfillan's project to establish a society devoted to the study of various social aspects of invention. The next section will provide more details about the scientific identity of the authors and how these notions are defined.

My relational approach to the epistolary corpus proposes considering the exchange between Merton and Gilfillan as one unit of an informal bimodal communicational network, that is a structure in which two types of "nodes" coexist (to use the standard terminology of the network analysis): I) the epistolary relation itself defined as a symmetric (non oriented) link between two scholars (A↔B); 2) the content markers (themes, names, etc.) which are cited by the two scholars in their letters and with which they are linked by an asymmetric (oriented) tie: ([A↔B] $\rightarrow \mathrm{a}, \mathrm{b}, \mathrm{c}, \ldots . . \mathrm{n}$.). Each letter, and by extension each epistolary relationship, can be considered as a generator of topics, names of individuals or organisations, publishers or journals, personal or collective events, etc.

The letter partially reproduced below illustrates my point (Box I). This letter was written by Gilfillan in June 1932. It is an answer to a previous letter from Merton, at that time a young graduate student at Harvard under the supervision of Sorokin, requesting information on the field of the sociology of invention. The symmetric tie is between the two main nodes of the epistolary relationship, Gilfillan $\leftrightarrow$ Merton. In his letter, Gilfillan mentions various topics, names, etc. He discusses his own work but also the achievements of the authors he considers as his "confrères": Sanders, Carr, Dickinson, Ogburn, etc. He emphasises some notions described as "promising", especially those of "duplicate invention", "invention by accident", "revolutionary invention”, "primitive invention”, etc. He quotes a series of organisations, journals and 


\title{
publishers. I consider all these elements (authors, concepts, organisations, journals) as content markers. Their tie with the Merton-Gilfillan's epistolary exchange is asymmetrical and it was sometimes necessary to simplify or trans- form them during the coding process.
}

\author{
Box I. Letter from Gilfillan to Merton, June st $^{\text {st }}$ ig32. \\ Dear Mr Merton, \\ I am glad to hear from you again and to send what little information I can in response to \\ your question of what our confreres are busy at.
}

[...] Sanders has not published anything in the field, nor I think has he been working on it for the last year or more. He was starting to trace statistically all manners of influences, from the industrial cycle, seasons, and social factors, considering also the delays between application and grant, but without application data by class, I think. His treatment would be highly statistical, supplemented by some consideration of foreign figures, and I think that one might say that he started or invented almost every possible statistical use of the US patent data in connexion with social factors. [...]

Lowell J. Carr [...] has a book about completed, with 3 chapters on invention which I have read. The chief basis of his study is a big questionnaire, covering the personality of inventors, their methods, obstacles, degrees of success and money reward, productivity, occupation, advice to young inventors that they would give, etc. [...] Prof Z.C.Dickinson [...] has not done anything recently that I know of but some very sound work in the Mich. Bus. Studies: Suggestions form Employes, Aug.1927; and industrial and commercial research, Nov 28. There is also his earlier Economic Motives.

My own work in my dissertation is all on the history of the ship, and the general principles or sociology of invention, almost always as to its causation, but a little as to its results. The latter field is particularly in need of cultivation. Ogburn's social change is the best thing in it, but quite lacking in statistics and proof. I think it will be hard to supply either until each invention considered is first defined, something never done and quite difficult.

Duplicate invention is an important point which Ogburn only makes a good start on, and which could be handled statistically. Invention by accident is another one such, on which I could send you a number of references. The personal traits of inventors in another field, on which Hart has made a start. How about the claim for instance, that revolutionary inventions are due to outsiders to the industry invented? I think I know the truth of it, Kaempffert has another idea, but no one has proved anything. His writings, by the way, should be attended to, unless you wish only statistical studies. 
Much more could be done in geographic comparisons that I or Jefferson have done, with statistical method. Race might also be investigated. Primitive invention is a field almost untouched on the inventor side, although there is an abundance of writing on the end products, the inventions. One should be something of an anthropologist to handle this. [...] The question of the economic interpretation of history is primarily that of the social effects of inventions, compared to other changes, which Ogburn has taken up without by any means concluding. A new contribution toit, still leaving tho the case unmeasured, is his chapter in the report of the Research Com'ee on Social Trends, for which I gathered the data. It is to be published in Nov. and cannot be shown meanwhile, I think. I made more extensive studies for it, that will not be used, of the influences of the automobile, liquid air and its factions, mechanical firing, rayon and other forms of dissolved cellulose, the milking machine, etc. [...] The matter of predicting inventions is one in which I have been particcularly interested for 26 years, and on which nothing scientific that I know of has been done, save my master's essay.

Hoping to be of help, thru these remarks or others, I remain,

Fraternally yours.

Figure I and Table 2 below present informations derived from this coding process. Figure I shows the whole coded set of nodes corresponding to the corpus $(n=209)$ and their respective situations within the Merton-Gilfillan's epistolary relationship. As they are omnipresent in the corpus, the categories of invention and patent were not used for coding. This graph helps visualise the global morphology of the corpus. It reveals a part of the asymmetry between Merton and Gilfillan: the diameter of the circles associated with Merton and Gilfillan being proportional to the number of letters sent by each. Moreover, this graph illustrates the uneven ability of the nodes to constitute principles of intellectual intercourse between both men. Obviously many markers are potentially shared in this epistolary relationship_contacted by Merton in the first period, Gilfillan is the most prolific correspondent of the two-but only a very limited number of these markers are real and lasting points of cognitive interaction: those specifically located in the intermediary area of the graph and which represent only I $4 \%$ of available nodes. 
Figure I. Thematic network of the epistolary relationship between Merton and Gilfillan (I932-1976)

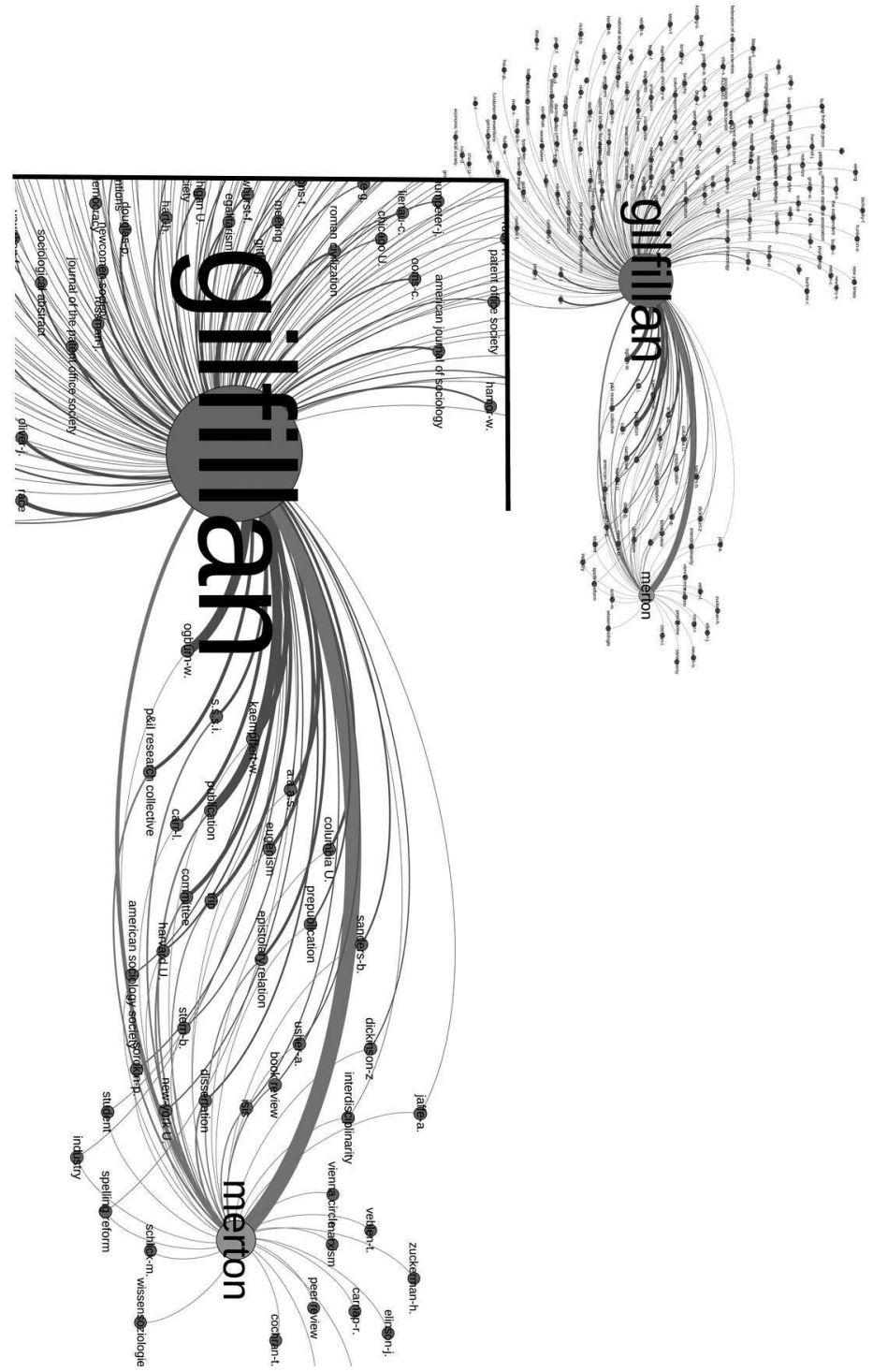

Nota: complete network (Top) and focus on the intermediary zone (Bottom). 
Table 2 below enumerates, once again by decreasing order of frequency, the main common nodes and their degree of specificity with respect to the whole set of available nodes.

Table 2. Main nodes of the corpus

\begin{tabular}{|c|c|c|c|}
\hline \multicolumn{2}{|l|}{ Total of nodes } & \multicolumn{2}{|l|}{209} \\
\hline \multicolumn{2}{|l|}{ Total of citation } & \multicolumn{2}{|l|}{453} \\
\hline \multicolumn{2}{|c|}{$\%$ of common nodes $(n=29)$} & \multicolumn{2}{|l|}{13.8} \\
\hline \multicolumn{2}{|c|}{$\begin{array}{c}\text { most cited nodes } \\
\text { (decreasing order, all nodes) }\end{array}$} & \multicolumn{2}{|c|}{$\begin{array}{l}\text { most cited nodes } \\
\text { (decreasing order, common nodes) }\end{array}$} \\
\hline NAMES CITED & $\begin{array}{c}\text { OTHERS } \\
\text { (organisations, journals, etc.) }\end{array}$ & NAMES CITED & $\begin{array}{c}\text { OTHERS } \\
\text { (organisations, journals, etc.) }\end{array}$ \\
\hline $\begin{array}{c}\text { Ogburn-W. } \\
\text { Kaempffert-W. } \\
\text { Carr-L. } \\
\text { Rossman-J. } \\
\text { Gittler-J. } \\
\text { Oliver-J. } \\
\text { Douglas-P. } \\
\text { Sanders-B. } \\
\text { Hamor-W. } \\
\text { Hart-H. }\end{array}$ & $\begin{array}{l}\text { Publication } \\
\text { Committee } \\
\text { P\&I Res. Coll. } \\
\text { S.S.S.I. } \\
\text { A.A.A.S. } \\
\text { Eugenism } \\
\text { Race } \\
\text { Columbia U. } \\
\text { AJS } \\
\text { Harvard U. }\end{array}$ & $\begin{array}{c}\text { Ogburn-W. } \\
\text { Kaempffert-W. } \\
\text { Carr-L. } \\
\text { Sanders-B. } \\
\text { Sorokin-P. } \\
\text { Stern-B. } \\
\text { Usher-A. } \\
\text { Dickinson-Z. } \\
\text { Jaffe-A. }\end{array}$ & $\begin{array}{c}\text { Publication } \\
\text { A.A.A.S. } \\
\text { Committee } \\
\text { P\&I Res. Coll. } \\
\text { Columbia U. } \\
\text { Eugenism } \\
\text { S.S.S.I. } \\
\text { Harvard U. } \\
\text { Prepublication } \\
\text { Americ. Socio. Soc. }\end{array}$ \\
\hline
\end{tabular}

Nota: set of all nodes left columns, set of common nodes, right columns.

Based on the general principle that a distinct node corresponds to each author (this equivalence is not true for subjects or themes), the first column of Table 2 reproduces exactly the order of the names already listed in Table I. By contrast, the two "others" columns demonstrate the nature of the coding process. For example, the node "P\&I research collective" (for "Patent and Innovation research collective") sums up all references made by Merton or Gilfillan to the existence or functioning of the invisible collective of the sociology of invention. The node "publication" does the same for all references to books, articles, chapters, etc. The node called "prepublication" merges all references to preprints, reports, preliminary manuscripts, etc. The node "committee" synthesises all references made to decision-oriented collegial structures related to organisations or learned societies such as the American Association for the Advancement of Science (A.A.A.S.) and its Section K (Social Sciences) in particular. 


\section{2. (RE)DISCOVERING THE SOCIOLOGY OF INVENTION}

Beyond the mapping of the thematic network, the previous section highlights the main markers (authors, concepts, etc.) that should direct the analysis of the intellectual, organisational and institutional background related to MertonGilfillan's correspondence. This reveals for instance the composition of the invisible college of Gilfillan's "confrères" in the analysis of the social aspects of invention. Besides Merton himself, these colleagues are mainly, by alphabetic order, Lowell Juilliard Carr, Zenas Clark Dickinson, Waldemar Kaempffert, William Fielding Ogburn, Joseph Rossman and Barkev Sanders.

This small academic network has a strong and dominant sociological orientation. It also has some interdisciplinary and occasional extra-academic components. Zenas Clark Dickinson, for example, was an economist. After receiving a $\mathrm{PhD}$ at in Harvard in 1920, he became assistant professor at the University of Minnesota in 1919 before moving to the University of Michigan in 1923 . He received a prize for his book Economic Motives (1922) on the psychological roots of economic theory. But it is mainly as the author of a book on industrial and commercial research that he shared Gilfillan's intellectual interests (Dickinson 1928). Joseph Rossman had an initial training in chemistry before working on his thesis in psychology. In the early 1930's he published a book on The Psychology of the Inventor (Rosmann, 1931). In this book he analysed the main results of a quantitative survey of a population of approximately 700 inventors, I80 patent attorneys, and 80 directors of research. Statistics are provided on the traits of inventors, their occupations, motives, source of livelihood, obstacles, occupations of fathers, inventiveness among relatives, marital status, etc. Gilfillan wrote an enthusiastic review of this work for the American Journal of Sociology (Vol. 38, No. 3, Nov., 1932). It is in the same journal that Rossman (1931a) published an article on the influence of war on civilian inventions. He claimed that although a military environment is not specifically conducive to invention, times of war are generally characterised by an extraordinary and unusual degree of inventiveness among civilians: "basic war inventions have been made chiefly by civilians”. Rossman was also the editor-in-chief of the Journal of the Patent Office Society — which later became the Journal of the Patent \& Trademark Office Society (Regan, 2003) — and in which Gilfillan published many articles. 
Barkev Sanders, whose family fled Turkey in 1915, was a PhD in statistics at Columbia University (1929). He spent most of his career in the public administration or government service, particularly in the departments of Health, Social Security and Justice. Gilfillan, who met Sanders in Columbia, mentioned in his correspondence Sander's methodological skills and general interest in a statistical approach of patents but also his difficulties in finding time for research. Waldemar Kaempffert was an editor and a populariser of science and invention. After working for the Scientific American, in 1927 he became the managing editor of the Science and Engineering section of the New York Times. In his article on the social destiny of the radio, Kaempffert stressed some of the social consequences of this technical invention. Just like the steam engine, the railway, the telephone, the telegraph or the postal service, radio may have profound social and political effects such as cultural homogenisation of distant populations through the generalisation of a single language: "In a generation radio can do more toward making English the language of the world than would be possible in a century of international railroading, telegraphing, and cabling" (Kaempffert, 1924, p.77I). In 1928, Kaempffert left New York for Chicago where he became the first director of the Chicago Museum of Science and Industry. Gilfillan would soon be appointed curator of ships for the Museum in addition to his position as associate researcher at the University of Chicago. In his correspondence, Gilfillan mentioned the project of a book on the history and social consequences of inventions with Kaempffert and part of what he considered as the "dirty work of research" done under his supervision.

In addition to Merton and Gilfillan, the main sociological core of this invisible college of invention consisted of Lowell Juilliard Carr and William Fielding Ogburn. After a first period as a reporter for the Detroit Free Press, Lowell Juilliard Carr decided to change his carreer and become a sociologist. Working under the supervision of Charles Horton Cooley, he became assistant professor of sociology at the University of Michigan in 1921. Carr devoted an important strand of his research to social change, invention and industry. In 1932 he published the results of a sociological survey on a random sample of I ooo patent holders (Carr, 1932). Patents were conceptualized as an 
intermediary object in order to capture cultural change and develop a comparative analysis of the level of productivity of inventors and scientists. In reference to Lotka's famous law on the frequency distribution of scientific productivity (Lotka, 1926), Carr observed that "multiple patenting seems to be somewhat more characteristic of inventors than multiple contributions is of scientists [...] more inventors seem likely to make multiple patents than scientists seem likely to make multiple contributions" (1932, p.576-577). William Fielding Ogburn has attracted considerable attention from historians of American sociology (Duncan, 1964 ; Bannister, 1987 ; Volti, 2004) and Innovation studies (McGee, 1995 ; Godin, 2008, 2010 ; Turner, 2008). Godin presents Ogburn and Gilfillan as the chief forgotten American sociological "forerunners" of innovation studies in an area whose history has been mainly written by economists ever since J. Schumpeter's inaugural contribution (Rosenberg, 2000)4 From Ogburn's perspective, invention studies are mainly concerned with social change: "The key to change may be sought in invention, [namely] any new element in culture [...]. To understand social change it is necessary to know how inventions are made and how they are diffused” (Ogburn, 1933).

Ogburn's main conceptual contribution was the concept of "cultural lag" designed to account for the absence of synchronism between the various parts or conditions of any culture. Describing the early stages (in 1915) of elaboration of this concept, Ogburn wrote of how he first tried to verify his hypothesis by considering the misadjustement between technology and law. Technology was then defined as an independant variable (for example the introduction of whirling machinery with rapidly moving wheels in factories) and law (for example the common laws concerning factory safety) as a dependent variable:

before the factory system $[\ldots]$ the machinery $[\ldots]$ had been simple tools $[\ldots]$ But after the coming of the factories in the United States, around I870, accidents continued to be dealt with by the old common law [...]. It was not until around I910 that employers' liability and workmen's compensation were adopted in this country. So that there was a lag of about thirty or forty years when the maladjust-

4 Godin (2008) observes that although Ogburn or Gilfillan may have been as important to the sociology of technology as Merton has been to the sociology of science, their contributions also "rehearsed" some of the main arguments developed during the $19^{\text {th }}$ century. 
ment could be measured by inadequate provision for several hundred thousand injuries and deaths to which there would have been a better adjustment if we had had laws of employers' liability or workmen's compensation (Ogburn, 1957, p.90).

Within this general approach to technology as an independent variable and to social norms, rules or structures as dependent variables (or adaptive culture), cultural lag theory has often been interpreted as a technologistic and determinist approach to social change ${ }^{5}$. Appointed as professor of sociology at Columbia University from 1919, Ogburn moved eight years later to the Department of Sociology at the University of Chicago. His academic responsibilities were at that time already substantial. In 1929, he served as the president of the American Sociological Society (which later changed its name to the American Sociological Association) — the first president of this association to have a full professional career as sociologist. From I930 to 1933 he was also director of research for President Hoover's Research Committee on Social Trends (Bulmer, 1983). It was within this committee on Social Trends that Ogburn and Gilfillan wrote a report on the social effects of inventions and discoveries (Gilfillan, Ogburn, 1933). This collaboration between Ogburn and Gilfillan is omnipresent in the epistolary corpus notably through the detailed description of research activities conducted at Ogburn's request ${ }^{6}$. The latter in turn publicly acknowledged the scientific value of his research assistant. In a book review for the American Journal of Sociology (42-I, 1936), he pointed out, while gently mocking the style and some eccentricities of their author ${ }^{7}$, the truly innovative nature of Gilfillan's books published in I935:

Mr. Gilfillan's books are pioneer studies but at the same time stand out in significance on the horizon among the few feeble efforts in the field [...] Future research workers on the sociology of invention will have to refer to Gilfillan, for his books are a landmark. Further researches undoubtedly will refine and

5 Ogburn explicitly rejected this interpretation of social change and attempted to generalise his theory: "A cultural lag is independent of the nature of the initiating part or of the lagging part, provided that they are interconnected" (1957, p.91).

6 Gilfillan was "research associate" at the University of Chicago. In 1946 he copublished with Ogburn a book on the social effects of aviation.

7 Gilfillan had a life-long interest in "reform spelling,». His correspondence, but also most of his books and articles adopt this reform by using terms such as "thru", "altho", "thot" or "brot". See for ex. box 1 . 
make more exact his observations, but such revision is needed in all pioneer books, which must range far, wide, and freely (ibid., p.I26-I29).

With the exception of Merton, all of the authors previously discussed (Carr, Dickinson, Kaempffert, Ogburn, Rossman, Sanders) were explicitly cited and thanked in the preface of The Socioloy of Invention for their respective contributions to the manuscript (proofreading, suggestions, corrections) ${ }^{8}$. In this preface, Gilfillan clearly outlined the interdisciplinary dimension of his project. The production of any robust knowledge on the social aspects of invention supposes an in-depth interaction between two main groups. The first group is mainly composed of inventors, engineers, physical scientists and patent lawyers. This group has undeniable knowledge about the craft of invention, its sciences and industries. But most of its members are ignorant of social science: "they do not even know when they stray into its garden, and their facile pronouncements on the social effects of causes of invention are normally traditional and without value" (I935, p.viii). The second group is composed of social scientists such as sociologists, economists, historians, etc. They generally try to observe, describe or explain various aspects of invention or engineering history but most frequently, as they are too little informed about the physical sciences or the business of invention, "without realising that they are in danger of wading beyond their depth, and they are likewise free with generalisations about inventions, which are untested, unreliable, and being commonly based on popular engineering stories of famous inventors" (p.viii). The main concern for Gilfillan is to find a way so that these two groups work together to develop a hybrid specialty at the crossroads of social science and engineering. The theoretical section of the book presents a formulation of the 38 principles (conceptual, theoretical, methodological statements, etc.) associated with this project. These principles are split into seven main parts: (A) the nature of invention, (B) changes evoking invention, (C) the rate of growth and life cycle of an invention, (D) factors fostering, retarding and locating invention, (E) principles of change, (F) inventors and other classes, and tendencies in the craft,

8 The book was at first published as a series of articles in the Journal of the Patent Office Society edited by Joseph Rossman. 
(G) effets on invention. Gilfillan defines invention as "a perpetual accretion of little details" (ibid., p.5) whose boundaries are arbitrarily settled by language and standardising habits in thought and industry: Invention is essentially a "complex of most diverse elements - a design for physical object, a process for working with it, the needed elements of science, if any ; the constituent materials, a method for building it, the raw materials used in working it [...] accumulated capital $[\ldots]$ skills, ideas $[\ldots]$, etc. $[\ldots]$ a new combination from prior art $[\ldots]$ that need not to be based on prior science" (ibid., p.6).

\section{FROM INTERACTION TO FAILED INSTITUTIONALISATION}

Why should sociologists of science bother with epistolary relationships? Does the correspondence between two (or more) scholars really give access to facets of academic life that are unreachable through other means, for example through the study of their publications or the range of informations derived from these publications? In this section, I propose to ascertain the sociological value of academic correspondence from three perspectives, each being related to a specific level of analysis. The first perspective, microsociological, is the interaction between Merton and Gilfillan and its main components-cognitive, moral and strategic. The second perspective, mesosociological, is the research network of Gilfillan and his "confrères": the invisible college of the invention that the analysis of the epistolary relationship helps to make visible. Finally, the third perspective is the organisational instrument created by Gilfillan- the Society for the Social Study of Invention - in the hope of establishing the social study of invention as an institutionalised field of research and more widely the organisational and institutional environment related to this instrument.

\section{I. THREE COMPONENTS OF AN ASYNCHRONOUS INTERACTION}

Exchange of letters is an elementary form of asynchronous interaction between two individuals. Now if it is true that any interaction involves some exchanges, some reciprocal adjustments, what is flowing or circulating between Merton and Gilfillan through their letters? I propose to distinguish analytically three components of this interaction: cognitive, normative and strategic. 
The first component, cognitive, is perhaps the most visible and trivial part of the interaction between Merton and Gilfillan. Their letters are an essential means of intellectual and scientific intercourse. Merton and Gilfillan both refer in their letters to many ideas, concepts, theories, hypotheses, methods, etc. generally related to the field of invention studies. Each letter is also an opportunity to exchange specific references to books, articles, reports, manuscripts etc. and is frequently accompanied with preprints or copies of articles recently published. No doubt that this cognitive circulation-in its intellectual (ideas, concepts, etc.) but also material (preprints, articles, etc.) dimensions-represents a distinctive feature of any academic correspondence compared to other types of correspondence.

Why did Merton get in touch with Gilfillan in early 1932? As a young graduate student working under the supervision of Sorokin at that time, Merton was preparing a Harvard seminar paper on the fluctuations in the field of inventions ${ }^{9}$. This initial seminar paper was never completed, due to the pressure of other work requested at the same time by Sorokin, but Merton kept in contact with Gilfillan and in May 1932 told him in a letter about his intention to write his doctoral dissertion in the field of invention:

Dear Mr Gilfillan,

[...] you thought me ungrateful in not fowarding a copy of my rather dismal attempt at an investigation of fluctuations in the field of invention. As a matter of fact, I never quite finished the paper [...] I have decided to write my doctoral dissertation in this field (I await P. Sorokin approval in an interview) Not wishing to work in the complete ignorance of what is being done by the contemporary researchers (such as yourself, Sanders, Carr, Dickinson) I am again venturing to trouble you. Could you tell me approximately what problem these men are concerned with at present? I would also welcome any general suggestion you may have the time and inclination to make (Letter from Merton to Gilfillan, May 27 ${ }^{\text {th }}$, 1932). 
Merton clearly displays what he expects from Gilfillan: to obtain some knowledge about the area of invention and its main contributors ; knowledge needed to rapidly locate the important issues - the "strategic research sites" to use a Mertonian terminology - that could be selected as main topics of his forthcoming doctoral dissertation. This repeated request explains partly the global morphology of my graph presented in the previous section (see Figure i): Gilfillan being regularly invited by Merton, at least during the first period of their epistolary relationship, to unilaterally transmit his knowledge and judgments about his main area of expertise. The two-page letter written by Gilfillan in response to Merton explicitly mentions this general principle of information "transfer":

Dear Mr Merton,

I am glad to hear from you again and to send what little information I can in response to your question of what our confreres are busy at (Letter from Gilfillan to Merton, June $\mathrm{I}^{\mathrm{st}}$, 1932).

Merton helped to maintain part of this asymmetry by choosing to interact with Gilfillan on a limited subset of all cited topics, but in a more sustainable way by cultivating throughout his career some degree of reticence about the influence of the founders of the sociology of invention on the definition of his own research orientations. In his Episodic Memoir (1977), Merton acknowledges Gilfillan as one of his few colleagues of the I930s, but he does not mention their epistolary relationship. He mainly emphasises the influence of his former Harvard professors, especially Henderson, Conan, and Sarton. Yet a reading of the letters sent by Gilfillan in 1932 suggests that the issues and research problems listed for Merton, generally in reference to the work of Ogburn, were far from irrelevant:

Duplicate invention is an important point which Ogburn only makes a good start on, and which could be handled statistically. Invention by accident is another one such, on which I could send you a number of references. [...] How about the claim for instance, that revolutionary inventions are due to outsiders to the industry invented? (Letter from Gilfillan to Merton, June ${ }^{\text {st }}$, 1932). 
The studies carried out in the I950s and I960s on simultaneous discoveries and quarrels over priority (Merton, 1957), serendipity (1949, 2004) or insiders and outsiders in science (1972) demonstrate that Merton took full consideration, in his own way and with his own theoretical framework, of the list of important research topics set out or him by Gilfillan in 1932. The repeated reference in his letters to Whitehead's famous formula - "Everything of importance has been said before by somebody who did not discover it"-here takes on its full meaning here. Hence its usefulness for enriching the Mertonian practice of "self-exemplification" (a reflexive variety of sociology of science) by analysing informal material such as an academic correspondence. It should be noted that in his analysis of the neglect of the sociology of science, Merton specifically used the concept of "duplicate invention" as a key example to discuss the lasting difficulty sociologists have had in developing a methodical approach to old ideas. The history of the inferences that have been drawn from the multiple and independent appearance of the same scientific discovery deserves some sociological attention: "first, this idea has been little elaborated or extended since it was emphasized by Ogburn and Thomas a generation ago and second, essentially the same idea regarding the sociological significance of multiple independent discoveries had been repeatedly formulated, particularly throughout the century before" (Merton, 1952, p.213-214).

The second general component of the interaction is normative. It refers first to the forms of epistolary communication, notably the stylistic codes adopted by the correspondents and their transformation due to the evolution of their respective social statuses and academic reputations. In 1932, Merton was a promising but unknown student whereas Gilfillan was already well-known for a few articles. The former wrote at that time to the latter with much deference:

Dear Mr Gilfillan,

If you remember at all the Harvard graduate student who sometimes ago burdened you with numerous inquiries concerning a sociological study of invention, it must be with a feeling of annoyance. [...] I trust you will not consider this continued imposition as an evidence of my lack of appreciation of your previous assistance (Letter from Merton to Gilfillan, May $27^{\text {th }}$ 1932). 
Forty years later, the situation was dramatically reversed. As Merton had just been elected member of the American National Academy of Sciences, Gilfillan who usually started his letters with a simple "Dear Merton" formula chose from then on to begin with a reference to professional status and to adopt a much more deferential tone:

Dear Prof. Merton,

May I add my congratulations on your election to the National Academy of Science, a rare honor for our science, and one that your work has well merited (Letter from Gilfillan to Merton, August 25 $5^{\text {th }}$ 1968).

In a symmetrical way, Merton's letters to Gilfillan frequently started during this period with a simple opening formula - “Dear Doctor Gilfillan”-implicitly emphasising their unequal academic status. If it is true that an informal communication mode such as a letter partially releases scientists from the constraints of public self-image, it obviously does not mean that this informal communication is free from the dynamics of social status.

The interaction between Merton and Gilfillan also captures another normative dimension omnipresent in their epistolary relationship, the moral "debt" and the need for the one who is indebted to repay it sooner or later. The sociology of science has extensively described the gift mode of exchange at work in the production of scientific knowledge and its diffusion. As Hagstrom has noted, in science as in many other social institutions, the acceptance of a gift by an individual or a community implies a recognition of the status of the donore and the existence of certain kinds of reciprocal rights: "These reciprocal rights may be to a return gift $[\ldots]$ or to certain appropriate sentiments of gratitude and deference" (Hagstrom, 1965, p.I3). Gilfillan showed that he was fully aware of this gift mode of exchange when in a letter (copy to Merton) to Paul Douglas, professor at Chicago University, he tried to prevent any sentiments of obligation:

Dear Prof Douglas,

As I promised the other day, I am sending you preprints of publications on invention that might interest you, with some other documents and some thoths that have occurred to me perhaps of value in your problems. Please do not feel obligated in return to send me an equal mass. of literature (Letter from Gilfillan to Douglas, July $15^{\text {th }}$, 1932). 
In 1971, as Gilfillan was involved in the controversy on eugenics through his publications on the social consequences of the use of lead technology (Gilfillan, 1965; 1990) ${ }^{10}$, he asked Merton, as well as many others academics, for a letter of endorsement of his scientific competence. In his response, Merton manifested his surprise about the necessity of this letter but accepted writing it as an implicit way to repay his own debt:

You put me in your debt once again, as you graciously did when I was still a graduate student, by placing me in the company of those to whom you dedicate your book. And now, by doing so again, you redouble my enjoyable debt to you. [...] What matters most at the moment is that To-whom-it-may-concern letter, I accept your statement that it would advance your cause to have such a letter and so I send it on. If you're right about the need for such a letter, it is a most depressing thought. Your own scholarship is the only susbtantial set of "credentials" that should be needed. But then you are beating up a storm, I suppose, in your thesis on eugenics, and perhaps you are right (Letter from Merton to Gilfillan, August 30 ${ }^{\text {th }}$, 197I).

The normative logic of gift and debt is conventionally associated with citational practices and expectations. In 1935, Merton published in The Quarterly Journal of Economics (49-3) his first article entitled Fluctuations in the rate of industrial invention. Shortly after, Gifillan sent him a letter in which he did not hide, even politely, a certain resentment:

Dear Merton,

I have just been reading your able article on Fluctuations [...] You show a real knowledge on invention [...] I am all the more sorry that I had not made you familiar with the writings of the best man hitherto on this subject, who is the overprinted and undersigned. My articles in the Jol. of the Pat. office Soc. for April and July 1934 cover much the same field. I wish that I had known of your article sooner, in order to improve my own book [...] and in order to cite your own. Let us keep closer in touch in the future (Letter from Gilfillan to Merton, July 19 ${ }^{\text {th }}$, 1935).

10 In the last part of his career Gilfillan was a fervent adept of the eugenics thesis. He thought he had made a major discovery on the socio-technical origins of the decline of Roman civilization notably through the analysis of series of bones collected on ancient Roman sites (1965, 1990). The letters of this period to Merton generally end with this formula: "Yours for not losing the race of the race". 
Merton's answer was rapidly sent:

Dear Gilfillan,

[... I am sorry that in my brief article on invention I did not refer to your work in the field. It was simply a case of neglecting the obvious (Letter from Merton to Gilffilan, July $23^{\text {rd }}$, 1935 ).

Gilfillan did not only reaffirm his priority in the field, he also invited Merton to do what he was supposed to do as an academic: to quote the author's name whose works or references had been useful for his own study. Moreover Gilfillan associated this reminder with the expression of a form of reciprocity: each citation generating potentially a citation in return. In short, by fulfilling his moral obligation Merton would serve at the same time his best self-interest.

This leads us to the third component of this asynchronous interaction-its strategic dimension - that is to say its ability to be a means to an end: the production and diffusion of ideas or research programs, but also the advancement of professional careers in a competitive academic market. As sure as there has been a long debate among sociologists about the balance between the normative and strategic roots of citational practice in science, there is little doubt that these two dimensions were intertwined in Gilfillan's expectations toward Merton's citational practice. By mixing moral obligation with self-interest - a form of axiological rationality - Gilfillan raised explicitly the possibility of a purely strategic use of citations or co-citations:

Let met know if I can help, with any citations (Letter from Gilfillan to Merton, July $19^{\text {th }}$ 1935).

More generally, Gilfillan used his letters as a possible means to request reviews of his books ${ }^{11}$ or various resources that were not directly reachable from Chicago. In 1934, he tried to extend his professional network at Harvard University and asked Merton to play an intermediary role by finding opportunities for lectures or meetings:

II In 1936, Merton published a review of the Sociology of Invention in the journal Isis. More than thirty years later, H. Zuckerman (1968) would review another book from Gilfillan for the journal Technology and Culture: Invention and the Patent System (1964). 
Harvard seems to be such a center, or the center, of interest in invention, that I have decided I shall have to pay it a visit [...] I wonder if there are any classes or clubs around Harvard or Boston that would like to hear me talk on some subject of inventions, without charge? I could throw together an informal talk, and I have a few lectures prepared. [...] If you would like to explore the possibilities for such lectures, or tell me to whom I should write, I should be greatly obliged (Letter from Gilfillan to Merton, May $16^{\text {th }} 1934$ ).

I have already had the opportunity to describe how Merton used his correspondence as an important means of strategic influence to advance his disciplinary program (Dubois, 20I4). In this specific case however the strategic component of the interaction with Gilfillan remains relatively unexplored. This relative disinterestedness on the Mertonian side is of course partly explained by the unequal status of Merton and Gifillan, at least in the last period of their epistolary relationship. As an eminent member of the higher stratas of the academic world, Merton didn't have much to expect from Gilfillan in terms of professional utility. But this disinterestedness may also be partly explained by the strong commitment of Gilfillan to eugenics in the late 1960s, Merton having little intellectual and ideological affinity with Gilfillan in this matter.

\subsection{MAKING VISIBLE THE INVISIBLE COLLEGE}

Since the contributions of Derek Price (1963) and Diane Crane (1969, I972), sociologists of science have attached great value to the identification of social circles or invisible colleges that sometimes announce the emergence of specialties or disciplines. Crane especially emphasised the importance of indirect interaction: the member of an invisible college or a social circle does not necessarily need to know a particular member of his circle in order to be influenced by him. A lot of interactions are mediated through intervening parties and face-to-face interactions may occur periodically only for a limited number of members of the same circle. Hence the definition of a social circle as characterised by "the presence of direct and indirect ties among many but not necessarily all of its members" (I972, p.43). 
The application of the various techniques of social network analysis to an epistolary corpus usefully supplements a purely bibliometric approach to scientific communication networks that tends to reduce social ties to formal aspects such as cosignature, citation or co-citation. Sander's case is revealing: although he was regularly interacting in the I93os with Gilfillan on the statistical measurement of patents, he had not at that time published any articles or books. An exclusively bibliometric approach to any scientific communication network tends automatically to ignore some of these important components that should be reconstructed through other methods. If the corpus is not yet rich enough to provide a fully detailed picture of the invisible college of invention, it nevertheless provides us with the possibility of describing the early forms of expression of an ephemeral research collective ${ }^{12}$.

A key issue for any sociologist of science is the production of the feeling of collective belonging. At what point do scientists stop thinking of themselves as individuals working in isolation from each other on the same subject? How do they express the early forms of their sense of common belonging ${ }^{13}$ ? It is always possible to partially answer these questions by studying publications alone. For example, I have noted repeatedly in this article that Gilfillan dedicated his sociology of invention to his "confrères" and that, in the preface of the same book, some of his close colleagues are thanked for their respective contributions to the final manuscript. As useful as they are, these explicit references are often only partial manifestations of a collective reconstructable in a less remote way through the epistolary material. In the case studied, the expression of the research collective appears inseparable from the recurrent reference to the existence of one research area defined as a set of research problems, concepts, theories, etc. collectively shared. This sense of common belonging is expressed in the most explicit way through the repeated use of the expression "our field": responding to your letter of the $7^{\text {th }}$, I am glad to see that you are going ahead in our little cultivated field (Letter from Gilfillan to Merton, June $16^{\text {th }} 1932$ ).

12 Such a full picture would imply the study of all the archives of the main members of the college of invention.

13 On this issue of the sense of common belonging in science, see Dubois, 2015 (forthcoming). 
I am looking forward to reading the Sociology of invention since I believe, after a comparison of your work with that of others in the field, that you have more to contribute than our fellow investigators (Letter from Merton to Gilfillan, July $23^{\text {th }}$ 1935).

I think we must organize and run ourselves, because no other group is sufficiently interested in our whole field to do it for us (Letter from Gilfillan to Merton, November $3^{\text {rd }}$ 1947).

In their letters, the correspondents frequently refer to various aspects of the early life of their research collective, including its direct and indirect origins. In connection with the preparation of a book review, Merton requested for example some information on the origins of Gilfillan's interest in the field of the invention, and particularly in the invention of ships:

You ask when I took up this study. When I was a freshman in college [...] I got the idea that I should devote my life to the problem of predicting the future of civilization for the next few centuries, also that this depended largely upon inventions. [...] [In Columbia] I met Ellsworth Huntington [...] and Prof. Simkhovitch, in whose course of Economic history (a brilliant teacher, he) I insisted on writing a term paper on the growth of inventions [...]. My interest in ships awaits a psychanalyst for explanation (Letter from Gilfillan to Merton, July 27 ${ }^{\text {th }}$ 1935).

These letters are also useful to identify some of the ordinary communication practices used by the group members in order to keep each other informed of their respective scientific advances, notably the sending of copies of letters:

I am sending copies of this letter to our confrères prof. L. J. Carr and Z. C. Dickinson and Sanders, since we are interested in each other elucubrations upon invention (Letter from Gilfillan to Merton, January $15^{\text {th }}$ I932).

These exchanges may be used as an indicator of the variability of the intensity of the relationship between group members:

in response to your question of what our confreres are busy at. I have not heard from any of them for some months, having been busy at other matters to write (Letter from Gilfillan to Merton, June $\mathrm{I}^{\text {st }}$ 1932). 
Finally, they also help to uncover the various attempts, sometimes unsuccessful, to sustainably institutionalise the research collective and the numerous difficulties related to this project. In the aftermath of World War II, Gilfillan tried to decisively advance the institutionalisation of the college of the sociology of invention through the creation of an organisational instrument: the Society for the Social Study of Invention (S.S.S.I.).

\subsection{DEMARCATION PROCESS AND PUBLIC IDENTITY}

Any research domain seeking collective recognition as a distinct specialty or discipline needs to distinguish itself, more or less explicitly, from the surrounding and pre-existing specialties or disciplines. Merton was right to point out that the early practioners of the sociology of science (and I may add the early practioners of the sociology of invention) had not acted differently from the founding fathers of sociology: "They found it necessary to demarcate their field from others if only to have a private sense, publicly expressed, of what they were up to. The cognitively and socially induced search for a public identity led them to delimit a jurisdiction distinctly their own" (1977, p.67). This "boundary work" (Gieryn, 1999) is generally closely associated with the production of some "instruments" devoted to the elaboration and diffusion of a collective and public identity. This abstract notion of "instrument" may of course encompass a great diversity of empirical phenomena: textbooks, research committees, journals, scholarly societies, etc. But whatever the form it takes, it allows those who control it to exert some strong constraints on the opportunity structure related to the emerging scientific collective and to become at least visible, if not legitimate, for those located outside of it.

The organisational instrument imagined by Gilfillan had only a very short period of life: established in December 1947, the S.S.S.I. was officially terminated in August 1949. Before its liquidation, the S.S.S.I. only managed to attract altogether 9 ordinary members who actually paid their $\$ 2$ fees. In 1949 , Gilfillan's disillusionment was obvious and probably inversely proportional to his early expectations. As mentioned in his first report, the S.S.S.I. was supposed to attract numerous members (between 300 and 700 according to the model 
of the Economic Historical Society created five years earlier) coming from different milieux: Academic (sociologists, economists, historians, psychologists, scientists and technologists interested in the social or historical aspects), Business and Technology (patent lawyers, inventors, industrialist), Government (patent officials, technologists in the Bureau of Standards) and Publicists (mainly popular science writers). The S.S.S.I. was also supposed to have its own journal:

a regular publication, some sort of a journal, must be our principal activity, and almost our first activity, a prerequisite for attracting wide support (Letter from Gilfillan to Merton, April $4^{\text {th }}$ 1947).

None of these goals was achieved. If Merton agreed for various reasons to follow Gilfillan in his organisational project, the S.S.S.I. was clearly a topic of disagreement between both men. At the time of the establishment of the organising committee of the future society, Merton was collectively nominated (just like W.F. Ogburn) as a possible chairman. Not only did Merton rapidly and clearly refuse this nomination but he repeatedly expressed to Gilfillan his general pessimism about the viability of the organisation and its development strategy:

I seriously doubt that it would be wise to establish an independent society at this time. I believe that there are too few people in the country who are devoting themselves fully to this area of intellectual interest. As a consequence, the membership which I would expect to be small in any case will have a considerable number of "part time adherents". I don't believe that this would make for a viable organization. I should myself favor the possibility of our being constituted as a special section or division of a society now in existence - the American Sociology Society or the A.A.A.S (Letter from Merton to Gilfillan, April $15^{\text {th }}$ 1947).

I rather doubt that there is a sufficiently large and active group of people vitally interested in the social study of invention to keep an organization of this kind viable. But such impressions are notoriously subject to error, and my pessimism does not preclude my interest. (Letter from Merton to Gilfillan, January $22^{\text {th }}$, 1948).

In these extracts, Merton suggests the nature of what would later be his long term strategy for the sociology of science-a strategy focusing on the existing professional organisations. More fundamentally, the epistolary exchanges related to the S.S.S.I. clearly show that such a project was based on a boun- 
dary work conceived to reduce as much as possible the risks of organisational rivalry. Two organizational structures played an important role in the general design of the academic positioning of the S.S.S.I.: Section K of the A.A.A.S. and the Newcomen Society:

This field is one of the principal subjects for section K, Social Science, of the American Association for the Advancement of Science [...] But this section $\mathrm{K}$ is weak, it has no organ of publication, it only meets once or twice a year [...] Other societies with aims overlapping ours, not affiliated so far as I know with AAAS, are the historical group - the American Hist. Asn., Ec. Hist. Soc., Newcomen Soc., Nautical Hist. Soc., Steamship Hist. Soc., Am. Neptune, Ry \& Loco. Hist. Soc., and probably other specialized groups. Sooner or later we should presumably have some contact with these groups, to learn if they consider us rivals, or think we should divide the field with them, or that we could cooperate in any of various possible ways. Of all these groups the Newcomen Soc. is our most extensive possible rival (Letter from Gilfillan to Merton, April $4^{\text {th }}$ 1947).

This organisational landscape described by Gilfillan is not unrelated to the lasting separation of the sociological studies of science and technology mentioned in my general introduction. Hence, among the many topics discussed at the time of the conception and the establishment of the organisation, one was the very name of the future society. Some members of the board of directors proposed the name Society for Studying the Social Aspects of Discoveries and Inventions. The collegial discussion related to this provisional name explicitly raised the issue of the combination of the social studies of science (discoveries) with technology (inventions) but also of the possibility of generating a single collective identity on the basis of this integration. The double issue was collectively discussed at a meeting in Chicago in December 1947 and a bit later, in a letter sent to Merton (absent at the Chicago meeting), Gilfillan summed up the main reasons behind the abandonment of the provisional name:

[the] proposal to include Discoveries, and presumably all the aspects of Science which we are considering for invention, was raised at the meeting too. But it has seemed to most of us that this would stretch our scope beyond our intellectual and organizational capacity, and also infringe on Sec. L (history and philosophy of science) [from the A.A.A.S.] (Letter from Gilfillan to Merton, January $8^{\text {th }}$, 1948). 
The risk is clearly formulated: not only could it mean going beyond the intellectual and organisational capacity of the college of invention, but more importantly it could create a direct rivalry with the historians and philosophers of science of section L. from the A.A.A.S. - at that time a much more structured and active section than the social science section. Retrospectively, and having in mind the long controversy between sociologists and philosophers in the I970s and I980s, this early assessment of the possible risk of rivalry between competitive perspectives in the study of science and technology was a premonition. The institutional separation between invention and discovery adopted by the founders of the S.S.S.I. gives some credit to a sociological hypothesis about the disjunction between the social studies of science and technology in the aftermath of World War II-a hypothesis that should however be corroborated by other empirical sources. Why did the early college of invention "officially" give up the study of discoveries and more broadly the study of science? Not so much for conceptual reasons (even if, as it was repeatedly claimed by Gilfillan, there is no necessary relation between invention and discovery) but mainly for organisational reasons to reduce as much as possible the risk of thematic overlap and thus academic rivalries. Differentiation and demarcation were supposed to ensure, at least in principle, the sustainability of the future society. Here we see at work the logic of differentiation specific to the "struggle for survival" in academia once described by Lemaine and Matalon (1969). The rapid disappearance of the S.S.S.I., two years after its creation, suggests however that this logic of differentiation remains a necessary but rarely sufficient condition for the sustainable public recognition of a research field.

\section{CONCLUSION}

Part of a broader effort to analyse the emergence of the study of science and technology, this article is devoted to one elementary unit of the Mertonian informal communication structure reconstructed from his correspondence archived at Columbia University. The study of the epistolary relationship between Merton and Gilfillan helps to deal in more sociological terms with the traditional (and mostly economic) genealogy of innovation 
studies (Godin, 20I0). It is also an opportunity to highlight a forgotten college of early practioners of the sociology of invention collaborating while being at the same time related to departments having different conceptions of sociology (Columbia and Chicago) and collectively promoting an interdisciplinary approach to science and technology at the intersection of the social and engineering sciences. More generally, the article invites sociologists to see scientific correspondence not only as a resource (even if it is sometimes a very useful resource) but also and above all as a sociological object in itself. I proposed to adopt a relational approach to the epistolary corpus mainly based on the conceptual and methodological tools elaborated within the social network analysis framework. This relational approach is closely associated with the qualitative and detailed analysis of the cognitive, normative, strategic and organisational dimensions inherent in most academic correspondence.

Author's Note: I wish to thank Benoît Godin (INRS - Canada) for his remarks on a draft version of this article, Alexandra Frenod (GEMASS / CNRS) and Peter Hamilton (Bardwell Press) for the careful reading of the manuscript.

\section{BIBLIOGRAPHY}

ABBOTT Andrew, 1999, Departement \& Discipline. Chicago Sociology at One Hundred, Chicago \& London, Chicago University Press.

BANNISTER Robert, 1987, Sociology and Scientism. The American Quest for Objectivity-1880-1940, Chapel Hill, The University of North Carolina Press.

BARBER Bernard, 1990, Social Studies of Science, New Brunswick, Transaction Publishers.

BARTMANSKI Dominik, 2012, "How to become an iconic social thinker: The intellectual pursuits of Malinowski and Foucault", European Journal of Social Theory, I5-4, p.427-453.

BIJKER Wiebke, HUGHES Thomas, PINCH Trevor (eds), 1987, The Social Construction of Technological Systems: New Directions in the Sociology and History of Technology, Cambridge MA, MIT Press. 
BULMER Martin, 1983, "The Methodology of Early Social Indicator Research: William Fielding Ogburn and 'Recent Social Trends', 1933", Social Indicators Research, 13-2, p.109-130.

CARR Lowell Juilliard, 1932, "The Patenting Performance of I 000 Inventors During Ten Years", American Journal of Sociology, 37-4, p.569-580.

CRANE Diane, 1969, "Social structure in a group of scientists: a test of the 'invisible college' hypothesis", American Sociological Review, 34, p.335-352.

-, 1972, Invisible Colleges. Diffusion of knowledge in scientific communities, Chicago, University of Chicago Press.

CUTCLIFFE Stephen, 2000, Ideas, Machine and Values, An Introduction to Science, Technology and Society Studies, Lanham-Maryland, Rowman \& Littlefield Publishers Inc.

DICKINSON Zenas Clark, 1928, Industrial and Commercial Research: Functions, Finances, Organization, University of Michigan, School of Business Administration, Bureau of Business Research.

DUBOIS Michel (dir.), 1994, Sociologie de l'envers. Éléments pour une autre histoire de la pensée sociologique, Paris, Ellipses.

-, 2014, “'Private knowledge' et 'programme disciplinaire' en sciences sociales: étude de cas à partir de la correspondance de Robert K. Merton", L’Année sociologique, 64-1, p.79-119.

-, 2015, "Invisible community and peerless science: case studies from Morocco and India", in G. Manzo (ed.), Festschrift in Honor of Mohamed Cherkaoui, Oxford, Bardwell Press [forthcoming].

DUNCAN Otis Dudley, 1964, "introduction", in William Ogburn, On Culture and Social Change, Chicago, The University of Chicago Press.

GIERYN Thomas, 1999, Cultural Boundaries of Science: Credibility on the Line, Chicago, The University of Chicago Press.

GILFILLAN Seabury Colum, 1935, The Sociology of Invention, Chicago, Follett Publishing Co.

-, 1935a, Inventing the Ship, Chicago: Follett Publishing Co. 
-, 1965, "Lead Poisoning and the Fall of Rome", Journal of Occupational Medicine, 7, pp.53-60.

-, 1990, Rome's Ruin by Lead Poison, Long Beach-CA, Wenzel Press.

GODIN Benoît, 2008, "Innovation: The History of a Category", Project on the Intellectual History of Innovation, Working Paper I.

-, 2010, "Innovation Without the Word: William F. Ogburn's Contribution to Technological Innovation Studies", Project on the Intellectual History of Innovation, Working Paper 5.

HAGSTROM Warren, 1965, The Scientific Community, New York, Basic Books.

KAEMPFFERT Waldemar, 1923, "Systematic Invention and Invention by

Wholesale", Forum, 70, p.2010-2018.

-, 1924, "The Social Destiny of Radio", The Forum, June, p.764-772.

KARADY Victor, "Stratégies de réussite et modes de faire-valoir de la sociologie chez les durkheimiens", Revue Française de Sociologie, 20-I, 1979, p.49-82.

LEMAINE Gérard, MATALON Benjamin, PROVANSAL Bernard, 1969, "La lutte pour la vie dans la cité scientifique", Revue Française de Sociologie, 10-2, p.139-165.

LOTKA Alfred, 1926, "The Frequency Distribution of Scientific Productivity", Journal of the Washington Academy of Sciences, XVI-12, p.317-323.

MACKENZIE Donald, WAJCMAN Judy (eds), 1985, The Social Shaping of Technology, Buckingham and Philadelphia, Open University Press.

MCGEE David, 1995, "Making up Mind: The Early Sociology of Invention", Technology and Culture, 36-4, p.773-80I.

MERTON Robert K., 1936, "The Sociology of Invention by S. C. Gilfillan", Isis, 25-I, p. $166-167$.

-, 1938, Science, Technology and Society in Seventeenth Century England, Osiris, 4, p.360-632.

-, 1949, "The Serendipity Pattern", in Robert K. Merton, Social Theory and Social Structure, Free Press, Glencoe (III.), p.103-108. 
-, 1952, "The neglect of the sociology of science", in Robert K. Merton, 1973, The sociology of science. Theoretical and empirical investigations, Chicago, The University of Chicago Press, p.210-220.

-, 1957, "Priorities in Scientific Discovery: A Chapter in the Sociology of Science", American Sociological Review, 22-6, p.635-659.

-, 1960, "Recognition and Excellence: instructive ambiguities", in Robert K. Merton, 1973, The sociology of science. Theoretical and empirical investigation, Chicago University Press, p.419-438.

-, 1972, "Insiders and Outsiders: A Chapter in the Sociology of Knowledge", American Journal of Sociology, 78-1, p.9-47.

-, 1977, "The sociology of science. An episodic Memoir", in The Sociology of Science in Europe, Robert K. Merton, Jerry Gaston (eds), Carbondale-ILL, Southern Illinois University Press, p.3-I4I.

-, 1985, On the Shoulders of the Giants. A Shandean Postcript, Harcourt Brace, The Vicennial Edition.

-, 1998, "Working with Lazarsfeld: Notes and contexts", in Paul Lazarsfeld (1901-1976). La sociologie de Vienne à New York, Jacques Lautman, Bernard-Pierre Lecuyer (eds), Paris, L'Harmattan, p.163-211.

-, THACRAY Arnold, 1972, "On discipline building: the Paradoxes of George Sarton", Isis, 63-4, p.472-495.

MERTON Robert K., BARBER Elinor, 2004, The Travels and Adventures of Serendipity. A Study in Sociological Semantics and the Sociology of Science, Princeton, Princeton University Press.

OGBURN William, 1933, "Social Change", in Encyclopedia of the Social Sciences, Seligman Edwin (ed.), New York, Macmillan, 3, p.330-334.

-, 1957, "Cultural Lag as Theory", Sociology and Social Research, Jan.-Feb. ; reprinted in William Ogburn, 1964, On Culture and Social Change. Selected papers, Chicago and London, The University of Chicago Press.

-, GILFILLAN Seabury Colum, 1933, "The influence of invention and discovery" in Recent social trends in the United States, ed. US President's Research Committee on Social Trends, New York, McGraw, I, p.122-166. 
OGBURN William, ADAMS Jean, GILFILLAN Seabury Colum, 1946, The Social Effects of Aviation, Boston, Houghton Mifflin Company, Riverside Press Cambridge.

PRICE Derek, 1963, Little science, big science, New York, Columbia University Press.

REGAN Maura, 2003, "Dr. Joseph Rossman and the Establishment of the Joseph Rossman Memorial Award", Journal of Patent \& Trademark Office Society, 85-II, p.76-78.

ROSENBERG Nathan, 2000, Schumpeter and the Endogeneity of Technology. Some American Perspectives, London and New York, The Graz Schumpeter lectures, Routledge.

ROSSMAN Joseph, 1931, The Psychology of the Inventor: A Study of the Patentee, Washington, Inventors Publishing Co.

-, 1931a, "War and Invention", American Journal of Sociology, 36-4, p.625-633.

TURNER Stephen, 2008, "The Social Study of Science before Kuhn", in The Handbook of Science and Technology Studies, Edward Hackett, Olga Amsterdamska, Michael Lynch, Judy Wajckman (eds), Cambridge Mass., MIT Press (third edition).

VOLTI Rudi, 2004, "William F. Ogburn, Social Change with Respect to Culture and Original Nature", Technology and Culture, 45-2, p.396-405.

WILLIAMS Robin, Edge David, 1996, "The Social Shaping of Technology", Research Policy, 25, p.865-899.

ZUCKERMAN Harriet, 1968, "Invention and the Patent System by S. C. Gilfillan", Technology and Culture, 9-1, p. 107-109. 